\title{
Reduced Serotonin-1A Receptor Binding in Social Anxiety Disorder
}

\author{
Rupert R. Lanzenberger, Markus Mitterhauser, Christoph Spindelegger, Wolfgang Wadsak, \\ Nikolas Klein, Leonhard-Key Mien, Alexander Holik, Trawat Attarbaschi, Nilufar Mossaheb, Julia Sacher, \\ Thomas Geiss-Granadia, Kurt Kletter, Siegfried Kasper, and Johannes Tauscher
}

Background: Results from studies in serotonin-1 A (5-HT $\left.\mathrm{H}_{\mathrm{A}}\right)$ knockout mice and previous positron emission tomography (PET) studies in humans imply a role for $5-\mathrm{HT}_{1 \mathrm{~A}}$ receptors in normal state anxiety as well as in certain anxiety disorders. The objective of this study was to investigate $5-\mathrm{HT}_{1 \mathrm{~A}}$ receptor binding potential (BP) in social anxiety disorder (SAD).

\begin{abstract}
Methods: Using PET and [carbonyl- ${ }^{11} \mathrm{C}$ ]WAY-100635, we compared a homogeneous group of 12 unmedicated, male SAD patients with 18 healthy control subjects $(\mathrm{HC})$. A multivariate ANOVA with all regional BP values as dependent variables, age and four radiochemical variables as covariates was performed.
\end{abstract}

Results: We found a significantly lower $5-\mathrm{HT}_{1 \mathrm{~A}} \mathrm{BP}$ in several limbic and paralimbic areas but not in the hippocampus ( $p=.234$ ) of SAD patients. The difference in $5-\mathrm{HT}_{1 A}$ binding was most significant in the amygdala $(-21.4 \% ; \mathrm{p}=.003)$. There was also a more than $20 \%$ lower $5-\mathrm{HT}_{1 \mathrm{~A}}$ BP of SAD patients in the anterior cingulate cortex $(p=.004)$, insula $(p=.003)$, and dorsal raphe nuclei $(p=.030)$.

Conclusions: The lower 5- $\mathrm{HT}_{1 \mathrm{~A}}$ binding in the amygdala and mesiofrontal areas of SAD patients is consistent with 1) preclinical findings of elevated anxiety in 5- $\mathrm{HT}_{1 \mathrm{~A}}$ knockout mice, 2) a previous PET study in healthy volunteers showing an inverse correlation between 5- $\mathrm{HT}_{1 \mathrm{~A}}$ BP and state anxiety, and 3) another human PET study in patients with panic disorder showing reduced 5- $\mathrm{HT}_{1 \mathrm{~A}}$ binding, thus corroborating the potential validity of $5-\mathrm{HT}_{1 \mathrm{~A}}$ receptors as targets in the treatment of human anxiety disorders.

Key Words: Affective disorders, anxiety, PET, serotonin, social phobia, STAl, 5- $\mathrm{HT}_{1 \mathrm{~A}}$

T he neurotransmitter serotonin $(5-\mathrm{HT})$ is involved in the regulation of mood and affective states. Drugs modulating the serotonergic system are widely used in the treatment of anxiety disorders and depression, and agonists of the serotonin-1A $\left(5-\mathrm{HT}_{1 \mathrm{~A}}\right)$ receptor have modest anxiolytic properties (Blier and de Montigny 1999). Recent studies in humans (Neumeister et al. 2004; Tauscher et al. 2001a), nonhuman primates (Bethea et al. 2005), and rodents (Gross and Hen 2004; Gross et al. 2002) suggest a central role for the $5-\mathrm{HT}_{1 \mathrm{~A}}$ receptor in the modulation of anxiety and fear. Neumeister et al. (2004) showed a significant reduction of $5-\mathrm{HT}_{1 \mathrm{~A}}$ receptor binding in the cingulate cortex and midbrain raphe nuclei in patients with panic disorder, indicating both lower presynaptic and postsynaptic $5-\mathrm{HT}_{1 \mathrm{~A}}$ receptor densities. The same research group reported no significant change in patients with posttraumatic stress disorder compared with healthy subjects (Bonne et al. 2005). Sullivan et al. (2005) reported an association between lower $5-\mathrm{HT}_{1 \mathrm{~A}}$ binding potential (BP) in patients suffering from major depression and comorbid panic disorder. In patients with chronic fatigue syndrome and elevated Spielberger State-Trait Anxiety Inventory (STAI) scores, a widespread reduction in $5-\mathrm{HT}_{1 \mathrm{~A}}$ receptor binding has been observed (Bailer et al. 2005).

From the Departments of General Psychiatry (RRL, CS, NK, AH, TA, NM, JS, TG-G, SK, JT) and Nuclear Medicine (MM, WW, L-KM, KK), Medical University of Vienna, Vienna, Austria; the Department of Pharmaceutical Technology and Biopharmaceutics (MM, L-KM), University of Vienna, Vienna, Austria; and Eli Lilly and Co. (JT), Lilly Research Laboratories, Indianapolis, Indiana.

Address reprint requests to Rupert Lanzenberger, M.D., Department of General Psychiatry, Medical University of Vienna, Währinger Gürtel 18-20, A-1090 Vienna, Austria; E-mail: rupert.lanzenberger@meduniwien.ac.at. Received March 29, 2006; revised May 27, 2006; accepted May 31, 2006.
In a previous study, we demonstrated a negative correlation between $5-\mathrm{HT}_{1 \mathrm{~A}}$ receptor $\mathrm{BP}$ and trait anxiety in healthy subjects (Tauscher et al. 2001a). This is in accordance with studies in $5-\mathrm{HT}_{1 \mathrm{~A}}$ receptor knockout mice demonstrating increased anxiety-like behavior in several tests (Gross et al. 2000; Parks et al. 1998; Ramboz et al. 1998). To differentiate between state and trait effects of $5-\mathrm{HT}_{1 \mathrm{~A}}$ receptor expression on the establishment of adult anxiety-like behavior, Gross et al. (2002) and Gross and Hen (2004) developed a transgenic mice model using timedependent and tissue-specific regulation of $5-\mathrm{HT}_{1 \mathrm{~A}}$ receptor expression. They revealed critical developmental periods for the establishment of adult anxiety behavior. These data suggest that early postnatal $5-\mathrm{HT}_{1 \mathrm{~A}}$ receptor levels, especially in the frontal cortex and hippocampus, are important factors in the development of adult anxiety thresholds.

Using positron emission tomography (PET) and the highly specific and selective $5-\mathrm{HT}_{1 \mathrm{~A}}$ receptor radioligand [carbonyl${ }^{11} \mathrm{C}$ ]WAY-100635, we have investigated the regional $5-\mathrm{HT}_{1 \mathrm{~A}} \mathrm{BP}$ in symptomatic patients suffering from social anxiety disorder (SAD) compared with a group of matched healthy control subjects for the first time. This study was focused on the limbic and paralimbic system including the amygdala, hippocampus, insula, cingulate, and orbitofrontal cortices, which have been shown to be hyperactive or hypoactive in anxiety disorders (Schneider et al. 1999; Talbot 2004; Tillfors et al. 2001) and anxious states (Benkelfat et al. 1995; Chua et al. 1999; Liotti et al. 2000). Given the stimulus-specific hyperreactivity of the amygdala in social phobia (Stein et al 2002; Tillfors et al. 2001; Veit et al. 2002; Wright et al. 2003) and the critical role of the amygdala in social fear conditioning (Morris et al. 2001; Pine et al. 2001; Robinson et al. 2005), we differentiated the hippocampal region from the amygdala in the mesiotemporal region. The anterior cingulate and orbitofrontal cortices were included in the predefined region of interest analysis because of the dense interconnections between it and the amygdala, the central role of the mesial frontal cortex in fear extinction (Amargos-Bosch et al. 
2004; Milad and Quirk 2002; Milad et al. 2004), and the integration of affective values of reinforcers (Kringelbach 2005).

\section{Methods and Materials}

\section{Subjects}

Fourteen medication-free male outpatients with social anxiety disorder and 18 healthy male control subjects were scanned with PET. Two patients were excluded from analysis: one because of drug consumption prior to the scan, discovered afterwards, and the second because of missing structural magnetic resonance imaging (MRI). Details of subject characteristics including psychometric assessment results are given in Table 1. All healthy subjects and most of the patients were recruited from the community via advertisements, with four patients being recruited from the outpatient clinic. Only male subjects were included in the study because of the influence of sex steroid hormones on the 5- $\mathrm{HT}_{1 \mathrm{~A}}$ receptor expression (Bethea et al. 2002; Bouali et al. 2003; Parsey et al. 2002) and the large between-subject 5- $\mathrm{HT}_{1 \mathrm{~A}}$ receptor variability that has been found in comprehensive investigations (Gunn et al. 1998; Rabiner et al. 2002). Consensus diagnoses according to DSM-IV-TR criteria were established by two psychiatrists performing a routine clinical interview, the Mini-International Neuropsychiatric Interview (MINI) (Sheehan et al. 1998), and the Spielberger State-Trait Anxiety Inventory (STAI) (Spielberger and Vagg 1984) on the day of the screening visit. The STAI was repeated on the day of the PET scan. All subjects underwent a medical examination including general physical and neurologic status, electrocardiogram, routine laboratory screening, and medical history at the screening visit to exclude subjects with relevant abnormalities, psychiatric comorbidities, and drug abuse. Six (50\%) of 12 patients also fulfilled the criteria for agoraphobia. None of the patients had major depression, because comorbid depression was an exclusion criterion, given the reduced $5-\mathrm{HT}_{1 \mathrm{~A}}$ receptor $\mathrm{BP}$ reported in several studies (Drevets et al. 1999; Parsey et al. 2006; Sullivan et al. 2005). To exclude treatment effects (Bhagwagar et al. 2004; Rabiner et al. 2000, 2002, 2004; Riad et al. 2004), it was ensured that patients were naïve to psychotropic drug treatment targeting the serotonergic system (except one who had ceased selective serotonin reuptake inhibitor [SSRI] medication 3 months prior to the PET

Table 1. Demographic and Clinical Characteristics, and Radiochemical Variables. Values Represent Mean $( \pm S D)$ in Healthy Control Subjects and Social Anxiety Disorder (SAD) Patients

\begin{tabular}{|c|c|c|}
\hline & $\begin{array}{l}\text { Control Subjects } \\
\quad(\mathrm{n}=18)\end{array}$ & $\begin{array}{l}\text { SAD Patients } \\
(\mathrm{n}=12)\end{array}$ \\
\hline \multirow[t]{2}{*}{ Age range (years) } & $19-44$ & $23-44$ \\
\hline & mean $\pm S D$ & mean $\pm S D$ \\
\hline Age (years) & $27.0 \pm 5.8$ & $30.3 \pm 6.4$ \\
\hline Body mass index $\left(\mathrm{kg} / \mathrm{m}^{2}\right), \mathrm{BMI}$ & $23.4 \pm 2.5$ & $25.0 \pm 4.1$ \\
\hline Spielberger State Anxiety Score, STAI ${ }^{a}$ & $32.4 \pm 4.5$ & $46.8 \pm 7.9$ \\
\hline Spielberger State Anxiety Score, STAI ${ }^{b}$ & $32.3 \pm 5,0$ & $43.8 \pm 7,8$ \\
\hline Spielberger Trait Anxiety Score, STAI ${ }^{a}$ & $34.3 \pm 6.6$ & $51.3 \pm 9.2$ \\
\hline Spielberger Trait Anxiety Score, STAI ${ }^{b}$ & $33.3 \pm 6,8$ & $48.5 \pm 9,4$ \\
\hline Activity Injected, ID (MBq) & $421.3 \pm 15.7$ & $398.7 \pm 35.2$ \\
\hline Radiochemical Purity, RCP (\%) & $97.8 \pm 1.4$ & $97.9 \pm 1.1$ \\
\hline Specific Activity (GBq/ $\mu \mathrm{mol})$ & $29.7 \pm 21.7$ & $23.4 \pm 13.9$ \\
\hline Weight of WAY $100634(\mu \mathrm{g})$ & $7.2 \pm 3.6$ & $5.1 \pm 2.9$ \\
\hline Weight of unlabeled WAY100635 $(\mu \mathrm{g})$ & $10.7 \pm 10.1$ & $11.2 \pm 10.3$ \\
\hline
\end{tabular}

${ }^{a, b}$ Spielberger State and Trait Anxiety Score, STAI ( $\left.\max =80\right) ;{ }^{a}$ screening visit, ${ }^{b} \mathrm{PET}$ day. scan). Both the patients and the healthy volunteers gave written informed consent after the procedures had been fully explained at the screening visit. The study was approved by the Ethics Committee of the Medical University of Vienna and the General Hospital of Vienna. All subjects received reimbursement for participation. No significant differences of demographic and radiochemical variables were found between the groups (unpaired $t$ test, $p>.05$, corrected)

\section{PET Scanning Protocol and Preprocessing}

Positron emission tomography scans were performed on a GE Advance PET scanner (General Electric Medical Systems, Milwaukee, Wisconsin) at the Department of Nuclear Medicine, Medical University of Vienna, Austria. The heads of subjects were positioned in the scanner parallel to the orbitomeatal line using a laser beam system to ensure the covering of the cerebellum in the field of view (FOV). Head movements were minimized with a polyurethane molded cushion and straps about the forehead and chin, and subjects were instructed not to move or speak during the measurement. A 5-minute transmission scan was performed in two-dimensional mode for correction of tissue attenuation using a retractable ${ }^{68} \mathrm{Ge}$ ring source. Dynamic PET scans were acquired in three-dimensional mode. Measurements started simultaneously with intravenous bolus injection of [carbonyl- ${ }^{11} \mathrm{C}$ WWAY-100635 in phosphate-buffered saline using an average dose of $5.37 \pm .86 \mathrm{MBq}$ per kilogram body weight. A series of 30 successive time frames $(15 \times 1$ minute, $15 \times 5$ minutes) were collected, resulting in a total acquisition time of 90 minutes. The emission data were scatter and attenuation corrected using the transmission data. Thirty-five contiguous slices (matrix $128 \times 128$ ) with a slice thickness of $4.25 \mathrm{~mm}$ were reconstructed using an iterative filtered back-projection algorithm (FORE-ITER). The spatial resolution of the final reconstructed volume was $4.36 \mathrm{~mm}$ full-width at half maximum (FWHM) at the center of the FOV. No realignment for head movement or partial volume correction was applied. The 30 frames of dynamic PET imaging were summed $\left(\mathrm{PET}_{\mathrm{ADD}}\right)$ for MRI-PET CO-registration.

\section{Radiochemistry}

[Carbonyl- ${ }^{11} \mathrm{C}$ ]WAY-100635 was prepared at the Cyclotron Unit of the PET center according to methods described previously (Matarrese et al. 2002; McCarron et al. 1996), with slight modifications, in a fully automated PET synthesizer (GE Healthcare, Uppsala, Sweden). Details of radiochemical variables are shown in Table 1. Injected activity, specific activity, radiochemical purity, weight of WAY-100634 (precursor), and weight of unlabeled WAY-100635 were used as covariates in the multivariate analysis of variance (ANOVA). The specific activity is defined as activity (GBq) per amount of substance (WAY 100635, $\mu \mathrm{mol}$ ) determined by high-performance liquid chromatography (HPLC). The values were corrected for the time of tracer administration.

\section{Magnetic Resonance Imaging}

High-resolution T1-weighted structural magnetic resonance (MR) images (magnetization-prepared rapid gradient-echo [MPRAGE] sequence, $256 \times 256$ matrix, $.78 \times .86 \mathrm{~mm}$ voxel size, slice thickness $1.56 \mathrm{~mm}, 128$ slices) were acquired in each subject using a 3 Tesla Medspec whole-body MR scanner (Bruker BioSpin, Ettlingen, Germany)

\section{Region of Interest Analysis}

The structural MRI images were co-registered to the PET ${ }_{\mathrm{ADD}}$ images and resliced using Statistical Parametric Mapping version 
2002 (SPM2; The Wellcome Department of Imaging Neuroscience, University College London; www.fil.ion.ucl.ac.uk/spm/) (Meyer et al. 1999). Regions of interest (ROIs) were defined a priori to enable comparison to other $5-\mathrm{HT}_{1 \mathrm{~A}}$ receptor studies (Bonne et al. 2005; Neumeister et al. 2004; Tauscher et al. 2001a) and based on the functional MRI and PET literature in anxiety disorders (Adolphs 2002; Liotti et al. 2000; Pine et al. 2001; Schneider et al. 1999; Tillfors et al. 2001) in areas expressing high levels of the 5-HT $\mathrm{HT}_{1 \mathrm{~A}}$ receptor (Rabiner et al. 2002; Varnas et al. 2004). Five ROIs in the anterior cingulate cortex, medial orbitofrontal cortex, insula, amygdala, hippocampus, and one reference region in the cerebellum were drawn bilaterally on coregistered MR images using the anatomical criteria established by Bremner et al. (1998). Due to the absence of MRI criteria for raphe boundaries, the raphe region in the midbrain was directly traced onto the $\mathrm{PET}_{\mathrm{ADD}}$ image. To delineate the dorsal raphe nucleus, we identified the slices showing the interpeduncular cistern on the triplanar view of co-registered MR images and placed a fixed-size cubic volume of interest (VOI) $\left(747 \mathrm{~mm}^{3}\right)$ over the area with highest signal on the corresponding PET $_{\mathrm{ADD}}$ slices (Abrams et al. 2004).

\section{Tracer Kinetic Modeling of [carbonyl- ${ }^{11}$ C]WAY-100635 Emission Data}

For quantification of the $5-\mathrm{HT}_{1 \mathrm{~A}}$ receptor $\mathrm{BP}$, we used the kinetic modeling tool of the biomedical image quantification software PMOD 2.7 (PMOD Technologies Ltd., Zurich, Switzerland) (Mikolajczyk et al. 1998). The simplified reference tissue model (SRTM), based on a two-tissue compartmental model (Gunn et al. 1998; Lammertsma and Hume 1996), was applied using the cerebellum as a reference region because of its low 5-HT $\mathrm{HA}_{1 \mathrm{~A}}$ receptor density (Burnet et al. 1997; Hall et al. 1997). Decay-corrected time activity curves (TACs) were obtained using the 30 frames of the dynamic PET data and the three-dimensional ROIs. We calculated the regional $\mathrm{BP}$ and the regional relative delivery of the radioligand normalized to the cerebellum (R1). Right and left ROIs were combined (except for the raphe region) to improve signal-to-noise ratio. The SRTM is sensitive to group differences in the radioligand kinetics of the reference region. We therefore examined the cerebellar TACs and found no significant group difference (two-tailed $t$ test, $p=.163$ ) between areas under the curve between cerebellar TACs of SAD patients and healthy control subjects.

\section{Statistical Analysis}

Statistical analyses were performed using SPSS 12.0.1 (SPSS Inc., Chicago, Illinois). The Kolmogorov-Smirnov test $(p>.05)$ for normal distribution and the Levene's test for equality of variance $(p>.05)$ were used prior to parametric statistical analyses. All parametric tests were two-tailed. Significance was set at $p<.05$. Pearson product moment correlation coefficients were calculated between regional BP values and demographic (age, body mass index) and radiochemical variables. To exclude any possible bias by summation effects, we included all radiochemical variables (see Table 1) as covariates in the multivariate ANOVA. Age-dependent reduction of $5-\mathrm{HT}_{1 \mathrm{~A}} \mathrm{BP}$ is a matter of debate (Rabiner et al. 2002; Tauscher et al. 2001b) and there may be age-dependent regional effects on perfusion and tracer delivery, so age was controlled for. A multivariate ANOVA with all regional BP values as dependent variables; group (patients versus control subjects) as a fixed factor; and age, injected activity, specific activity, weight of WAY-100634, and radiochemical purity as covariates was performed. To exclude the influence on regional $\mathrm{BP}$ of tracer delivery differences between groups, we performed an additional multivariate ANOVA with all regional R1 values as dependent variables, group as a fixed factor, and age and the four radiochemical variables as covariates. When significant group-by-region differences for BP values were obtained with ANOVA, post hoc $t$ tests (unpaired, two-tailed, alpha level $p$ $<.05)$ in eight ROIs were calculated. Significance levels were corrected for the multiple comparisons involved in employing eight ROIs. The Bonferroni adjusted $p$ value was $p<.00625$. A Pearson product moment correlation and partial correlations controlling for age and radiochemical variables between anxiety scores (STAI) and regional $5-\mathrm{HT}_{1 \mathrm{~A}} \mathrm{BP}$ were performed (twotailed, $p<.05)$.

\section{Results}

\section{Comparison Between SAD Patients and Healthy Control Subjects}

The multivariate ANOVA revealed a significant reduction of $5-\mathrm{HT}_{1 \mathrm{~A}} \mathrm{BP}$ in SAD patients compared with healthy control subjects ( $p=.041$; Pillai's Trace). Including age and radiochemical variables as covariates in the multivariate ANOVA, we found a highly significant reduction in $5-\mathrm{HT}_{1 \mathrm{~A}}$ binding in the amygdala $(p=.003 ;-21.4 \%$, uncorrected for multiple comparison, post hoc $t$ test), in the anterior cingulate cortex $(p=.004 ;-23.8 \%)$, and in the insula $(p=.003 ;-28.0 \%)$, and a significant reduction in the raphe region $(p=.030 ;-36.4 \%)$ and the medial orbitofrontal cortex $(p=.032 ;-18.4)$. Applying a Bonferroni correction for multiple comparisons, the amygdala region $(p=.024)$, the insula $(p=.024)$, and the anterior cingulate cortex $(p=.032)$ remained significant. Details are given in Table 2 . Excluding age as a covariate in the multivariate ANOVA, we found a highly significant group difference in the anterior cingulate cortex $(p=$ $.003)$, insula $(p=.002)$, and amygdala $(p=.004)$, and a significant difference in the raphe nuclei $(p=.025)$ and the medial orbitofrontal cortex $(p=.028)$, indicating a minor effect of age. To exclude possible bias introduced by ROI drawing, we additionally used a fixed size VOI in the amygdala and calculated a multivariate ANOVA, which further improved the significance level ( $p=.001 ;-23.8 \%$ group difference) of the post hoc $t$ test. There was no relevant improvement applying a fixed size VOI in the hippocampal head ( $p=.234 ;-9.7 \%$ to $p=.210 ;-11.5 \%)$. Parametric $5-\mathrm{HT}_{1 \mathrm{~A}}$ receptor binding potential maps superimposed on co-registered T1-weighted MR images are shown in Figure 1. Figure 2 shows scatter histograms of the $5-\mathrm{HT}_{1 \mathrm{~A}}$ receptor $\mathrm{BP}$ values comparing patients with healthy control subjects.

An additional ANOVA with all regional R1 values as dependent variables and age as a covariate showed no significant group effect $(p=.504)$. Including the radiochemical variables additionally as covariates showed no significant effect $(p=.361)$. Both ANOVA results indicate no bias due to tracer delivery differences between groups. No significant correlations $(p<.05$, corrected) between 5- $\mathrm{HT}_{1 \mathrm{~A}}$ BP or R1 and demographic as well as radiochemical variables were found. There were no significant group differences between the SAD patients and the healthy control subjects concerning age, body mass index, and radiochemical variables.

To investigate the effect of comorbid agoraphobia on $5-\mathrm{HT}_{1 \mathrm{~A}}$ $\mathrm{BP}$, we performed calculations on subgroups. Excluding the six SAD patients with comorbid agoraphobia reduced the significance levels of the multivariate ANOVA only slightly $(p=.075$, $n=24$; controlled for age and radiochemical variables). Exclud- 
Table 2. Regional 5- $\mathrm{HT}_{1 \mathrm{~A}}$ Receptor Binding Potential Values in SAD Patients and Healthy Controls

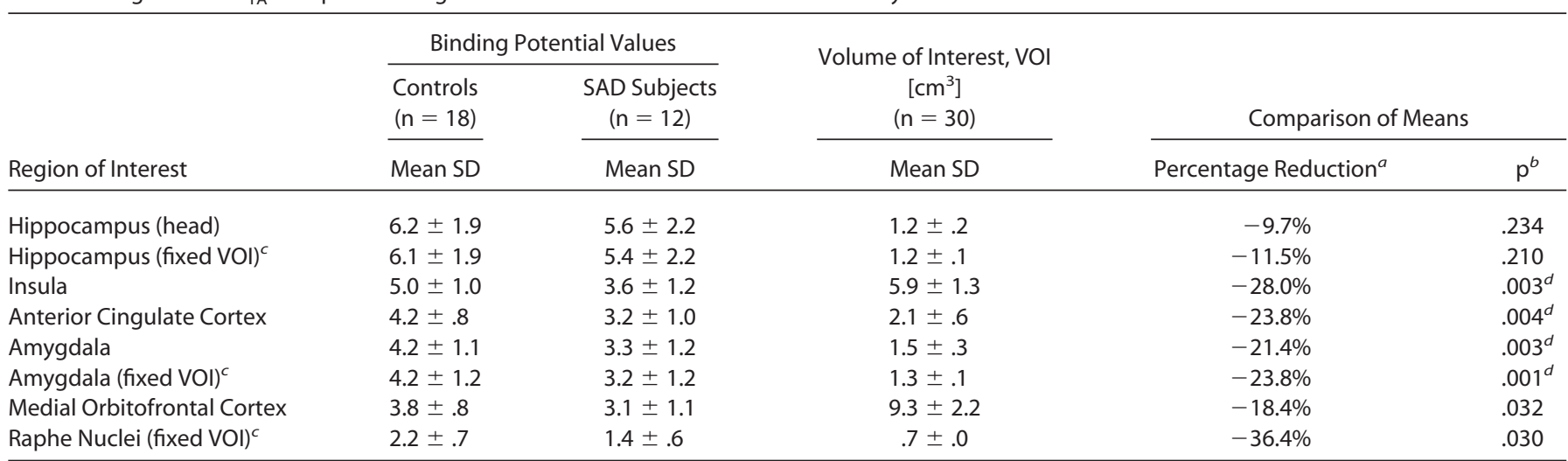

${ }^{a}$ Calculation of mean $\mathrm{BP}$ reduction: $\left(100 * \mathrm{BP}_{\text {patients }} / \mathrm{BP}_{\text {controls }}\right)-100$.

${ }^{b}$ Significance levels corrected for age and four radiochemical covariates as indicated in the statistical section (post hoc $t$ tests, ANOVA).

cfixed VOI, fixed size for volume of interest.

${ }^{d} p$ values surviving the Bonferroni correction for multiple comparison implying eight ROIs ( $p<0.00625$; Bonferroni adjusted $p$ value at 8 ROIs).

ing the six SAD patients without comorbid agoraphobia dramatically reduced the significance level of the multivariate ANOVA $(p=.387, n=24)$.

\section{Relationships Between Anxiety Scores (STAI) and Regional 5-HT ${ }_{1 \text { A }}$ Receptor Binding Potential}

Spielberger State-Trait Anxiety Inventory scores obtained at the screening visit and on the day of the PET scan were significantly lower in the patient than the healthy control group $(p<.001)$. Details are given in Table 1. State and trait scores on both days correlated significantly $(p<.001)$. A Pearson correlation analysis revealed no significant correlation between state or trait anxiety scores and regional $5-\mathrm{HT}_{1 \mathrm{~A}} \mathrm{BP}$ in both groups. A partial correlation controlling for age and radiochemical variables also showed no significant relationship between $5-\mathrm{HT}_{1 \mathrm{~A}}$ binding and anxiety scores. As shown in Figure 3, the values in the correlation plot are clustered into two groups, differentiating clearly between social anxiety disorder patients and healthy control subjects.

\section{Discussion}

We have demonstrated a significantly lower $5-\mathrm{HT}_{1 \mathrm{~A}}$ receptor binding potential in male patients suffering from SAD than in an age-matched healthy control group. Significant $5-\mathrm{HT}_{1 \mathrm{~A}}$ BP reductions (corrected for multiple tests) were found in the amygdala $(-21.4 \%)$, the anterior cingulate cortex $(-23.8 \%)$, and insula $(-28.0 \%)$, indicating alterations in limbic and paralimbic areas of SAD patients. The reduction was most prominent in the raphe nuclei $(-36.4 \%)$ but did not survive correction for multiple testing in this area. Given the inclusion criteria of our subjects, we can exclude the possibility that the reduction in $5-\mathrm{HT}_{1 \mathrm{~A}} \mathrm{BP}$ was caused by exposure to psychotropic drugs or comorbid depression (Bailer et al. 2005; Drevets et al. 1999; Sargent et al. 2000; Sullivan et al. 2005). Our results are partly concordant with a recently published study in panic disorder patients (Neumeister et al. 2004). This group showed a reduction in $5-\mathrm{HT}_{1 \mathrm{~A}}$ receptor binding of $27.6 \%$ in the anterior cingulate cortex, comparable with our result of $23.8 \%$. In contrast to our study, they found no difference in the anterior insula and mesiotemporal cortex including both the hippocampus and amygdala. We differentiated the amygdala from the hippocampus region a priori because of comprehensive literature emphasizing the central role of the amygdala in neural processing of fear and anxiety. Investigating six regions of interest, we found the most significant group difference in the amygdala, suggesting an area-specific effect on serotonergic transmission in SAD. Given the high percentage $(50.0 \%)$ of comorbid agoraphobia in the patient sample, our results could be thought to reflect a main effect of agoraphobia on reduced 5- $\mathrm{HT}_{1 \mathrm{~A}} \mathrm{BP}$. The subgroup analysis detailed in Results did not support the view that our results could reflect effects attributable solely to agoraphobia, although the small sample size might limit its validity.

\section{Modulation of Amygdala Activity by Mesiofrontal Areas}

Given the central role of the amygdala in fear conditioning and processing (Adolphs et al. 2005; Morris et al. 2001), we expected and found significant differences in $5-\mathrm{HT}_{1 \mathrm{~A}}$ binding of the amygdala region between SAD patients and control subjects. The amygdala is strongly modulated by mesiofrontal areas. The anterior cingulate cortex and neighboring prefrontal areas control the attention to threat-related stimuli and inhibit amygdala activity by top-down regulation (Bishop et al. 2004). In rats, destruction of ventral prefrontal cortex blocks recall of fear extinction, indicating the storage of long-term extinction memory in paralimbic areas and not in the amygdala (Milad and Quirk 2002). Studies in nonhuman primates have confirmed the central role of the anterior cingulate region (Kalin et al. 2005) and the orbitofrontal cortex (Kalin and Shelton 2003) in the regulation of amygdala activity. Increased amygdala activity is associated with diminished activation of the mesiofrontal cortex in anxiety disorders (Shin et al. 2005). The exaggerated amygdala responsiveness frequently shown in functional magnetic resonance imaging (fMRI) studies investigating SAD patients (Birbaumer et al 1998; Lorberbaum et al. 2004; Schneider et al. 1999; Tillfors et al. 2002) might be associated with alterations of the serotonergic system in mesiofrontal areas. Several functional studies have reported increased or altered amygdala activation to facial stimuli in social phobia, confirming the specific association of faces with anxiety in this disorder. A recently published PET study of panic disorder patients demonstrated a lack of appropriate top-down regulation of the orbitofrontal region on amygdala activity (Kent et al. 2005). These results in limbic and paralimbic regions are consistent with our data, which demonstrate area-specific $5-\mathrm{HT}_{1 \mathrm{~A}}$ alterations in anxiety circuitry including the amygdala, anterior cingulate, and orbitofrontal cortices. 

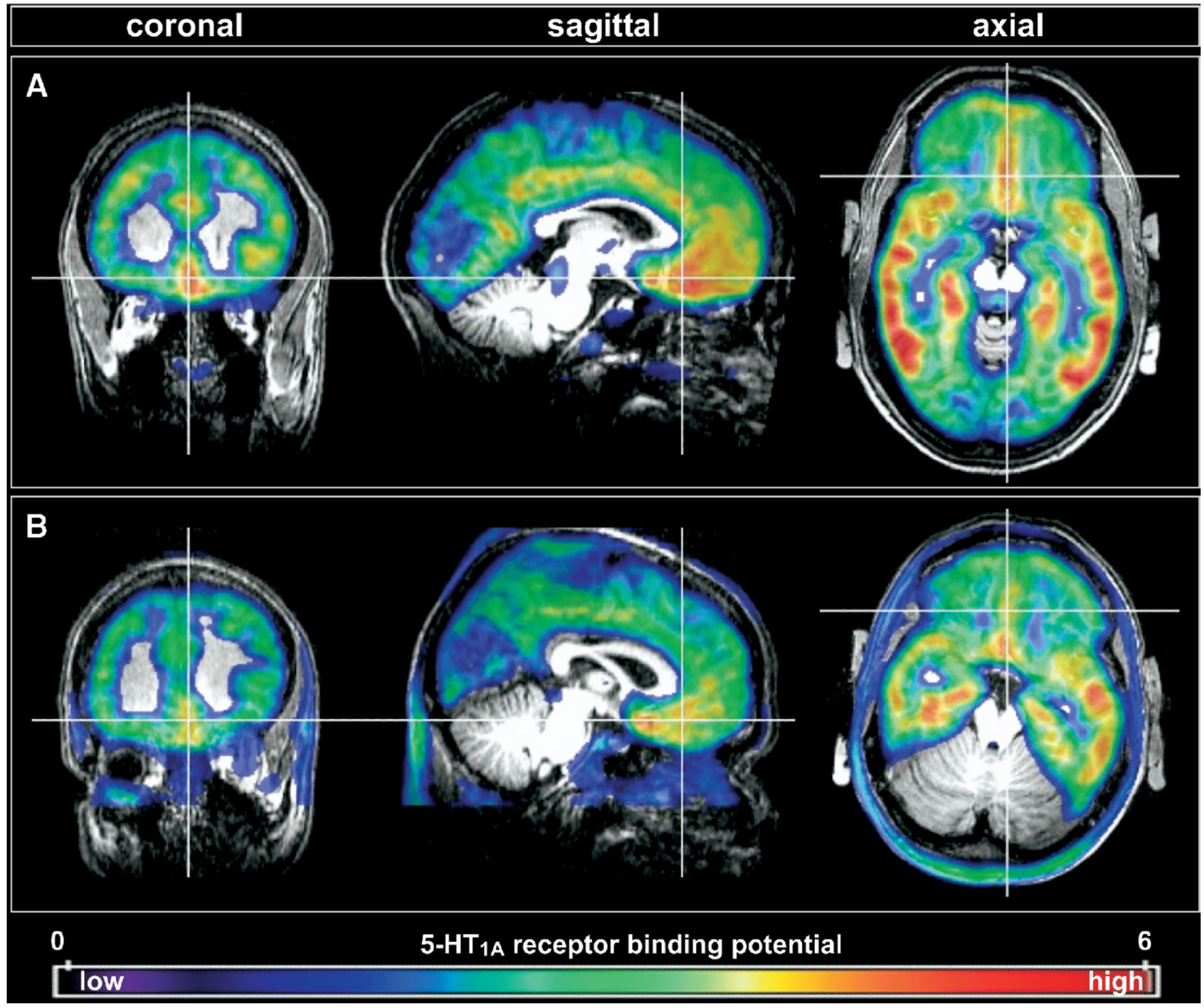

Figure 1. Parametric $5-\mathrm{HT}_{1 \mathrm{~A}}$ receptor binding potential (BP) maps superimposed on the co-registered T1-weighted MR images of a single healthy subject (A) compared with a representative patient suffering from social anxiety disorder (SAD) (B). White cross in the triplanar view (coronal, sagittal, axial) indicates the corresponding area in the mesial orbitofrontal cortex. The color table indicates the $5-\mathrm{HT}_{1 \mathrm{~A}}$ receptor binding potential values. 5- $\mathrm{HT} \mathrm{TA}_{1 \mathrm{~A}}$, serotonin-1A; $\mathrm{BP}$ binding potential; MR, magnetic resonance; SAD, social anxiety disorder.

\section{The Function of the Insula Region in the Anxiety Circuitry}

In SAD patients, we found a significantly lower 5- $\mathrm{HT}_{1 \mathrm{~A}}$ receptor binding in the insula region, including the anterior and posterior parts, in the region of interest analysis. Neumeister et al. (2004), investigating the anterior insula, did not find lower $5-\mathrm{HT}_{1 \mathrm{~A}}$ receptor binding in patients with panic disorder in this region. The same group reported no significant reduction in 5- $\mathrm{HT}_{1 \mathrm{~A}}$ binding in the anterior insula when investigating patients with posttraumatic stress disorder (Bonne et al. 2005). Given the important role of the polymodal insula region in the anxiety circuitry, we would expect changes of serotonergic transmission in this region. Patients suffering from social phobia had increased activity in the insula, amygdala, pons, and temporal pole, and decreased activity in the anterior cingulate and prefrontal cortex in an fMRI paradigm using anticipatory anxiety (Lorberbaum et al. 2004). Chua et al. (1999), investigating healthy subjects with fMRI, revealed an area-specific activiation pattern restricted to the insula, orbitofrontal region, anterior cingulate, and temporal cortices in anticipatory anxiety. Anxiety in healthy subjects was associated with specific activations in the ventral insula, orbitofrontal cortex, and anterior temporal region (Liotti et al. 2000). To summarize, functional data suggest the specific and strong involvement of the insula and mesiofrontal region in processing of anxiety consistent with our finding of reduced $5-\mathrm{HT}_{1 \mathrm{~A}}$ receptor binding.

\section{The 5- $\mathrm{HT}_{1 \mathrm{~A}}$ Receptor in the Hippocampus}

In the hippocampus, we found no group difference in $5-\mathrm{HT}_{1 \mathrm{~A}}$ receptor binding between patients and healthy control subjects. This is consistent with functional neuroimaging studies in healthy subjects (Benkelfat et al. 1995; Chua et al. 1999; Liotti et al. 2000), patients suffering from anxiety disorders (Bonne et al. 2005; Kent et al. 2005; Tillfors et al. 2001; Wright et al. 2003), and studies in nonhuman primates (Kalin et al. 2004, 2005). These studies have 


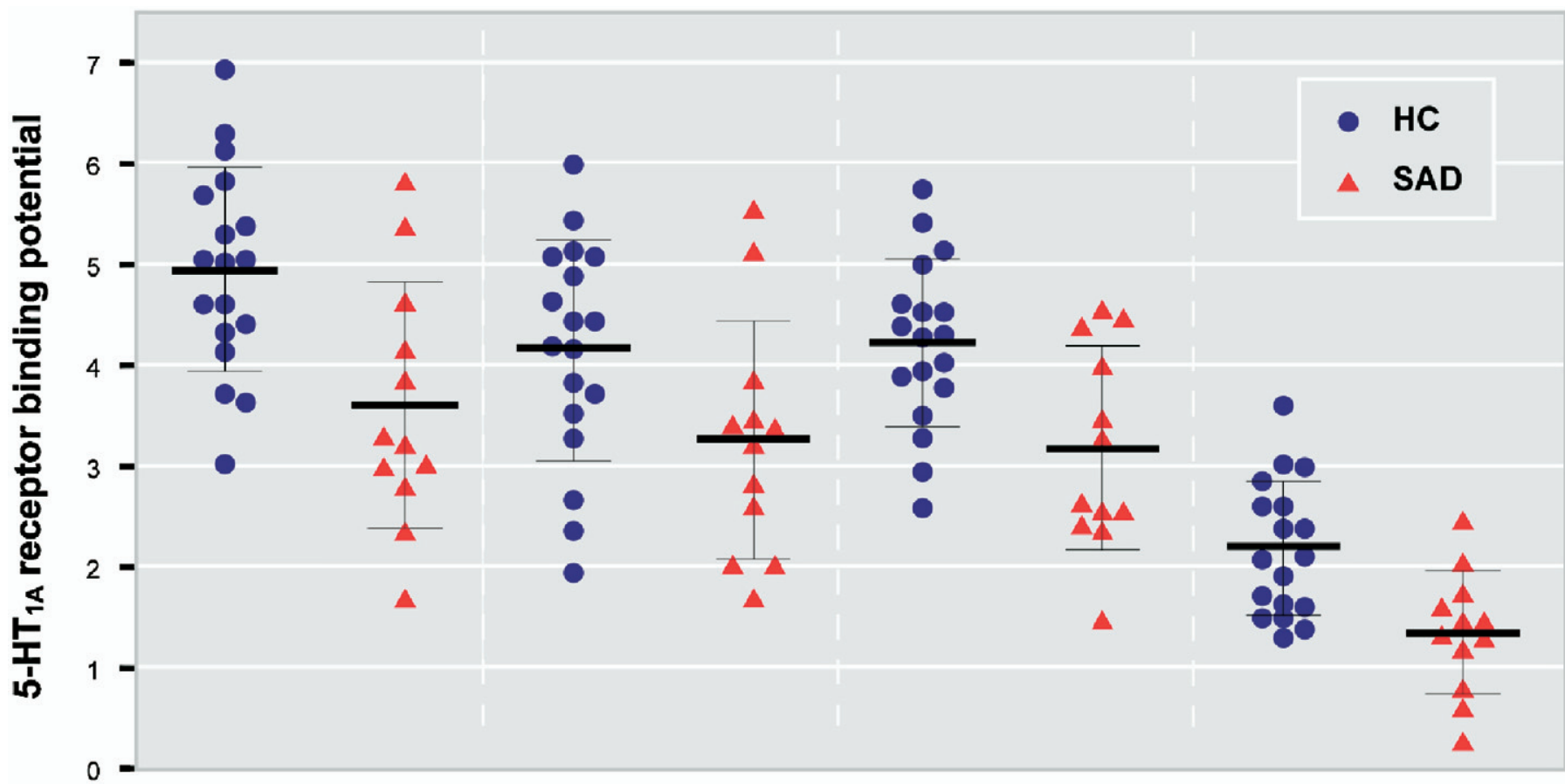

\section{Insula \\ Amygdala \\ Anterior Cingulate \\ Raphe nucleus}

Figure 2. Scatter histograms of the $5-\mathrm{HT}_{1 \mathrm{~A}}$ receptor $\mathrm{BP}$ values for healthy control subjects $(\mathrm{HC}=\bullet$, blue, $n=18)$ and patients suffering from social anxiety disorder $(\mathrm{SAD}=\boldsymbol{\Delta}$, red, $n=12)$. Mean $( \pm \mathrm{SD})$ bars indicate the significant differences between SAD and control group in the insula $\left(p=.003^{*}\right)$, amygdala $(p=$ $\left..003^{*}\right)$, anterior cingulate cortex $(p=.004)$, and raphe nucleus $(p=.030)$. Asterisk $(*)$ indicates significant values $(p<.05)$ after adjustment for multiple comparison (Bonferroni correction) implying six ROls. $5-\mathrm{HT}_{1 \mathrm{~A}}$, serotonin-1A; BP, binding potential; $\mathrm{HC}$, healthy control subjects; SAD, social anxiety disorder; $\mathrm{ROI}$, region of interest.

shown that the hippocampus is not a central part of anxiety circuitries. To exclude possible effects of hippocampal and amygdala size differences between the groups, we additionally calculated the binding potential using fixed volumes of interest (1.2 $\mathrm{cm}^{3}$ for the hippocampus, $1.3 \mathrm{~cm}^{3}$ for the amygdala). The significance levels were slightly higher in the amygdala $(p=.003$ to $p=.001)$ and the hippocampus $(p=.234$ to $p=.210)$, indicating that no bias was introduced in the manual tracing of ROIs on co-registered MR images. Given the long PET measurement time of 90 minutes, a relevant underestimation of BP by late binding equilibrium in receptor-rich regions such as the hippocampus or insula is unlikely (Parsey et al. 2000; Tauscher et al. 2002).

\section{Anxiety Scores and Regional 5- $\mathrm{HT}_{1 \mathrm{~A}}$ Binding}

Investigating 30 subjects, we found no significant relationship between either trait or state anxiety scores (STAI) and regional $5-\mathrm{HT}_{1 \mathrm{~A}} \mathrm{BP}$ in male SAD patients and healthy control subjects. These results are consistent with the comprehensive PET study published by Rabiner et al. (2002) performing the STAI in 66 healthy male subjects. In addition, Neumeister et al. (2004) compared patients suffering from panic disorder to healthy control subjects (67.7\% female subjects) using the Panic Disorder Severity Scale (PDSS) and did not report a correlation between PDSS scores and regional $5-\mathrm{HT}_{1 \mathrm{~A}}$ binding. Investigating patients with chronic fatigue syndrome and healthy control subjects, Cleare et al. (2005) also found no significant correlation between STAI scores and regional $5-\mathrm{HT}_{1 \mathrm{~A}}$ receptor binding in $21 \mathrm{ROIs}$. We reported an inverse relationship between $5-\mathrm{HT}_{1 \mathrm{~A}}$ receptor binding and anxiety scores in a group of 19 healthy subjects (42\% female subjects) using the Revised NEO Personality Inventory (Tauscher et al. 2001a). However, none of the correlations in the four ROIs delineated (prefrontal, parietal, occipital, and anterior cingulate cortices) survived a correction for multiple comparisons (Tauscher et al. 2001a). In addition, Sullivan et al. (2005) recently reported a positive correlation between $5-\mathrm{HT}_{1 \mathrm{~A}}$ binding and anxiety scores in 28 patients with major depressive disorder (MDD) including comorbid anxiety disorders (43\%) and found lower $5-\mathrm{HT}_{1 \mathrm{~A}} \mathrm{BP}$ in MDD patients with comorbid anxiety disorder than in those with MDD only. It is possible that our finding of no significant relationship between regional $5-\mathrm{HT}_{1 \mathrm{~A}} \mathrm{BP}$ and patients' anxiety scores arises because of insufficient statistical power, with a sample size of only 12 . Given the high intersubject variability of 5-HT $1 \mathrm{~A}$ BP (Gunn et al. 1998; Rabiner et al. 2002) and the strong effects of steroid hormones on $5-\mathrm{HT}_{1 \mathrm{~A}}$ receptor expression (Bethea et al. 2002; Parsey et al. 2002), the results in our homogeneous group of 18 male control subjects do not support a significant relationship between trait or state anxiety and $5-\mathrm{HT}_{1 \mathrm{~A}} \mathrm{BP}$ in the amygdala, hippocampus, insula, anterior cingulate, and orbitofrontal cortices in healthy male subjects.

\section{The Relationship Between Postsynaptic 5-HT ${ }_{1 \mathrm{~A}}$ Levels and Serotonergic Neurotransmission}

The $5-\mathrm{HT}_{1 \mathrm{~A}}$ receptor is the major inhibitory serotonergic receptor on glutaminergic and gamma-aminobutyric acid (GABA)ergic neurons in the frontal cortex (Amargos-Bosch et al. 2004; Puig et al. 2005; Santana et al. 2004). In addition, 5-HT $\mathrm{H}_{1 \mathrm{~A}}$ receptors are involved in the control of serotonergic neurons in the dorsal raphe nuclei by the medial prefrontal cortex (Celada et al. 2001, 2002), suggesting an important feedback mechanism 

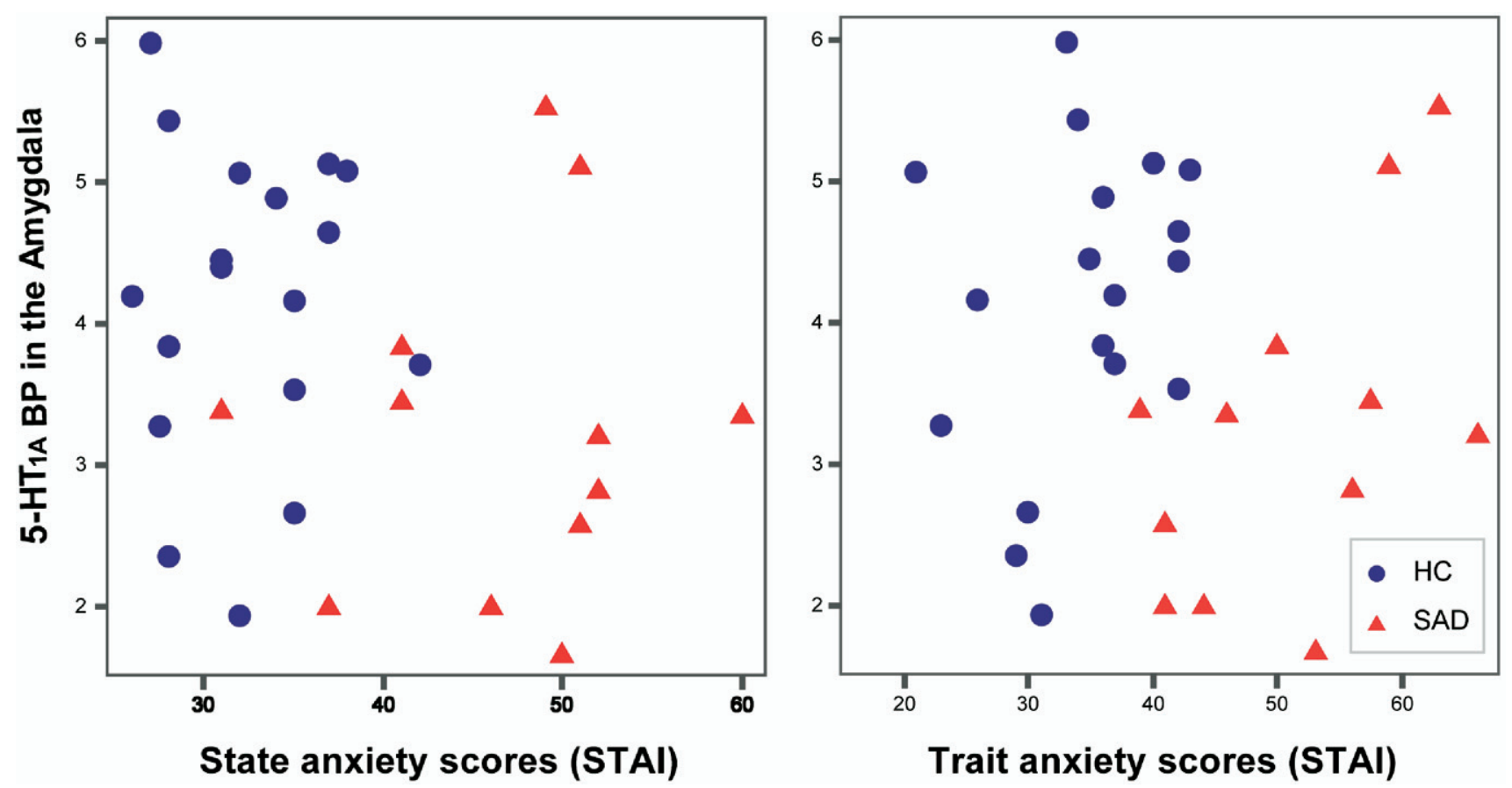

Figure 3. Relationship between $5-\mathrm{HT}_{1 \mathrm{~A}}$ receptor BP values in the amygdala and the Spielberger State-Trait Anxiety Inventory state (left) and trait (right) anxiety scores. Values are clustered into two groups, and grouping differentiates between social anxiety disorder (SAD) patients ( $\mathbf{\Lambda}$, red) and healthy control subjects $\left(\bullet\right.$, blue). There was no significant correlation between STAl state or trait scores and 5-HT ${ }_{1 A}$ binding in patients (SAD) and healthy control subjects (HC). 5 - $\mathrm{HT}_{1 \mathrm{~A}^{\prime}}$ serotonin-1 A; BP, binding potential; STAI, Spielberger State-Trait Anxiety Inventory; SAD, social anxiety disorder; HC, healthy control subjects.

between serotonergic firing in the raphe region and prefrontal activity. Therefore, the balance of inhibitory $5-\mathrm{HT}_{1 \mathrm{~A}}$ and excitatory serotonin-2A $\left(5-\mathrm{HT}_{2 \mathrm{~A}}\right)$ receptors strongly influences the effects of serotonergic firing on glutaminergic and GABAergic neurons in the frontal cortex but also in the amygdala, hippocampus, and insula (Martin-Ruiz et al. 2001). Pharmacological studies in rodents have shown the anxiolytic effect of both $5-\mathrm{HT}_{1 \mathrm{~A}}$ agonism and 5- $\mathrm{HT}_{2 \mathrm{~A}}$ antagonism (Delgado et al. 2005). Lower postsynaptic $5-\mathrm{HT}_{1 \mathrm{~A}}$ receptor levels reduce the inhibitory influence of serotonergic neurons on glutaminergic and GABAergic neurons in the frontal cortex (Amargos-Bosch et al. 2004; Santana et al. 2004). Increased serotonergic phasic firing by reduced presynaptic $5-\mathrm{HT}_{1 \mathrm{~A}}$ receptor levels in the raphe nuclei and increased serotonergic excitatory influence on glutaminergic and GABAergic neurons might shift the serotonergic influence on frontal neurons. Lower $5-\mathrm{HT}_{1 \mathrm{~A}}$ receptor levels might be induced by a downregulation mechanism in the adult subject, e.g., by hormonal influence on receptor expression (Andrade et al. 2005; Bethea et al. 2002, 2005; Bouali et al. 2003; Fernandes et al. 1997; Meijer and de Kloet 1998) or congenital and genetic effects (Gross and Hen 2004; Gross et al. 2002). Downregulation of $5-\mathrm{HT}_{1 \mathrm{~A}}$ receptors in the anterior cingulate cortex, insula, and amygdala suggests an area-specific regulation of $5-\mathrm{HT}_{1 \mathrm{~A}}$ receptor expression in these areas involved in processing of anxiety-associated stimulation. Given the lower 5- $\mathrm{HT}_{1 \mathrm{~A}}$ BP in depression (Bhagwagar et al. 2004; Drevets et al. 1999; Sargent et al. 2000), reduced 5-HT $\mathrm{HA}_{1 \mathrm{~A}}$ receptor levels might increase the vulnerability for affective disorders, including both anxiety disorders and depression. Our data are not sufficient to differentiate between neuroplastic processes on $5-\mathrm{HT}_{1 \mathrm{~A}}$ receptor expression in glutaminergic and GABAergic neurons and primarily reduced $5-\mathrm{HT}_{1 \mathrm{~A}}$ receptor levels changing the serotonergic influence on frontal and limbic neurons. In addition, steroid hormones such as glucocorticoids regulate the $5-\mathrm{HT}_{1 \mathrm{~A}}$ receptor expression by transcriptional repression of the receptor promoter sequence (Meijer et al. 2000). Dysregulations of the hypothalamic-pituitary-adrenal (HPA) axis have been frequently shown in anxiety disorders and depression. Therefore, reduced $5-\mathrm{HT}_{1 \mathrm{~A}}$ receptor levels and changes in the serotonin system across different types of anxiety disorders and depression might be caused by HPA axis dysregulation.

\section{Conclusion}

The main finding of this PET study is a significantly lower 5- $\mathrm{HT}_{1 \mathrm{~A}}$ receptor binding in patients suffering from social anxiety disorder compared with healthy control subjects, indicating an altered serotonergic neurotransmission in SAD and specifically implicating $5-\mathrm{HT}_{1 \mathrm{~A}}$ receptors as a potential target of interest for novel therapeutics to treat this condition. These results further emphasize the central role of the amygdala, the mesiofrontal cortex, and the polymodal insula in the modulation of anxious states.

This research was supported by Grants from the Austrian Science Fund (P16549) and the National Alliance for Research on Schizophrenia and Depression (NARSAD) to JT and a Grant from the Austrian National Bank (OENB P11468) to RRL.

We are grateful to M. Willeit, D. Hussey, and U. Bailer for discussions. We thank A. Konstantinidis, A. Schosser, J. Kindler, and H. Nassan-Agha for blood sampling and subject screening assessments. We are especially indebted to C. Poetzi and C. Novotny for clinical support and M. Paul, G. Dobrozemsky, G. Wagner, B. Reiterits, I. Leitinger, and R. Bartosch for technical support during the positron emission tomography (PET) scans.

Parts of this work were presented at the American College of Neuropsychopharmacology (ACNP), December 2005, Hilton Waikoloa Village, Waikoloa, Hawaii. 
Abrams JK, Johnson PL, Hollis JH, Lowry CA (2004): Anatomic and functional topography of the dorsal raphe nucleus. Ann N Y Acad Sci 1018:46-57.

Adolphs R (2002): Neural systems for recognizing emotion. Curr Opin Neurobiol 12:169-177.

Adolphs R, Gosselin F, Buchanan TW, Tranel D, Schyns P, Damasio AR (2005): A mechanism for impaired fear recognition after amygdala damage. Nature 433:68-72.

Amargos-Bosch M, Bortolozzi A, Puig MV, Serrats J, Adell A, Celada P, et al. (2004): Co-expression and in vivo interaction of serotonin $1 A$ and serotonin $2 \mathrm{~A}$ receptors in pyramidal neurons of prefrontal cortex. Cereb Cortex 14:281-299.

Andrade TG, Nakamuta JS, Avanzi V, Graeff FG (2005): Anxiolytic effect of estradiol in the median raphe nucleus mediated by 5-HT1A receptors. Behav Brain Res 163:18-25.

Bailer UF, Frank GK, Henry SE, Price JC, Meltzer CC, Weissfeld L, et al. (2005): Altered brain serotonin 5-HT1A receptor binding after recovery from anorexia nervosa measured by positron emission tomography and [carbonyl11C]WAY-100635. Arch Gen Psychiatry 62:1032-1041.

Benkelfat C, Bradwejn J, Meyer E, Ellenbogen M, Milot S, Gjedde A, et al. (1995): Functional neuroanatomy of CCK4-induced anxiety in normal healthy volunteers. Am J Psychiatry 152:1180-1184.

Bethea CL, Lu NZ, Gundlah C, Streicher JM (2002): Diverse actions of ovarian steroids in the serotonin neural system. Front Neuroendocrinol 23:41100.

Bethea CL, Pau FK, Fox S, Hess DL, Berga SL, Cameron JL (2005): Sensitivity to stress-induced reproductive dysfunction linked to activity of the serotonin system. Fertil Steril 83:148-155.

Bhagwagar Z, Rabiner EA, Sargent PA, Grasby PM, Cowen PJ (2004): Persistent reduction in brain serotonin $1 \mathrm{~A}$ receptor binding in recovered depressed men measured by positron emission tomography with [11C]WAY-100635. Mol Psychiatry 9:386-392.

Birbaumer N, Grodd W, Diedrich O, Klose U, Erb M, Lotze M, et al. (1998): fMRI reveals amygdala activation to human faces in social phobics. Neuroreport 9:1223-1226.

Bishop S, Duncan J, Brett M, Lawrence AD (2004): Prefrontal cortical function and anxiety: Controlling attention to threat-related stimuli. Nat Neurosci 7:184-188.

Blier P, de Montigny C (1999): Serotonin and drug-induced therapeutic responses in major depression, obsessive-compulsive and panic disorders. Neuropsychopharmacology 21(suppl 2):91S-98S.

Bonne O, Bain E, Neumeister A, Nugent AC, Vythilingam M, Carson RE, et al. (2005): No change in serotonin type $1 \mathrm{~A}$ receptor binding in patients with posttraumatic stress disorder. Am J Psychiatry 162:383-385.

Bouali S, Evrard A, Chastanet M, Lesch KP, Hamon M, Adrien J (2003): Sex hormone-dependent desensitization of 5-HT1 A autoreceptors in knockout mice deficient in the 5-HT transporter. Eur J Neurosci 18:2203-2212.

Bremner JD, Bronen RA, De Erasquin G, Vermetten E, Staib LH, Ng CK, et al. (1998): Development reliability of a method for using magnetic resonance imaging for the definition of regions of interest for position emission tomography. Clin Positron Imaging 1:145-159.

Burnet PW, Eastwood SL, Harrison PJ (1997): [3H]WAY-100635 for 5-HT1A receptor autoradiography in human brain: A comparison with $[3 \mathrm{H}] 8-\mathrm{OH}-$ DPAT and demonstration of increased binding in the frontal cortex in schizophrenia. Neurochem Int 30:565-574.

Celada P, Puig MV, Casanovas JM, Guillazo G, Artigas F (2001): Control of dorsal raphe serotonergic neurons by the medial prefrontal cortex: Involvement of serotonin-1A, GABA(A), and glutamate receptors. J Neurosci 21:9917-9929.

Celada P, Puig MV, Martin-Ruiz R, Casanovas JM, Artigas F (2002): Control of the serotonergic system by the medial prefrontal cortex: Potential role in the etiology of PTSD and depressive disorders. Neurotox Res 4:409-419.

Chua P, Krams M, Toni I, Passingham R, Dolan R (1999): A functional anatomy of anticipatory anxiety. Neuroimage 9:563-571.

Cleare AJ, Messa C, Rabiner EA, Grasby PM (2005): Brain 5-HT1A receptor binding in chronic fatigue syndrome measured using positron emission tomography and [11C]WAY-100635. Biol Psychiatry 57:239-246.

Delgado M, Caicoya AG, Greciano V, Benhamu B, Lopez-Rodriguez ML, Fernandez-Alfonso MS, et al. (2005): Anxiolytic-like effect of a serotonergic ligand with high affinity for 5-HT1 A, 5-HT2A and 5-HT3 receptors. Eur J Pharmacol 511:9-19.

Drevets WC, Frank E, Price JC, Kupfer DJ, Holt D, Greer PJ, et al. (1999): PET imaging of serotonin $1 \mathrm{~A}$ receptor binding in depression. Biol Psychiatry 46:1375-1387.
Fernandes C, McKittrick CR, File SE, McEwen BS (1997): Decreased 5-HT1A and increased 5-HT2A receptor binding after chronic corticosterone associated with a behavioural indication of depression but not anxiety. Psychoneuroendocrinology 22:477-491.

Gross C, Hen R (2004): The developmental origins of anxiety. Nat Rev Neurosci 5:545-552.

Gross C, Santarelli L, Brunner D, Zhuang X, Hen R (2000): Altered fear circuits in 5-HT(1A) receptor KO mice. Biol Psychiatry 48:1157-1163.

Gross C, Zhuang X, Stark K, Ramboz S, Oosting R, Kirby L, et al. (2002): Serotonin $1 \mathrm{~A}$ receptor acts during development to establish normal anxiety-like behaviour in the adult. Nature 416:396-400.

Gunn RN, Sargent PA, Bench CJ, Rabiner EA, Osman S, Pike VW, et al. (1998): Tracer kinetic modeling of the 5-HT1A receptor ligand [carbonyl11C]WAY-100635 for PET. Neuroimage 8:426-440.

Hall H, Lundkvist C, Halldin C, Farde L, Pike VW, McCarron JA, et al. (1997): Autoradiographic localization of 5-HT1 A receptors in the post-mortem human brain using [3H]WAY-100635 and [11C]way-100635. Brain Res 745:96-108.

Kalin NH, Shelton SE (2003): Nonhuman primate models to study anxiety, emotion regulation, and psychopathology. Ann NY Acad Sci 1008:189-200.

Kalin NH, Shelton SE, Davidson RJ (2004): The role of the central nucleus of the amygdala in mediating fear and anxiety in the primate. $J$ Neurosci 24:5506-5515.

Kalin NH, Shelton SE, Fox AS, Oakes TR, Davidson RJ (2005): Brain regions associated with the expression and contextual regulation of anxiety in primates. Biol Psychiatry 58:796-804.

Kent JM, Coplan JD, Mawlawi O, Martinez JM, Browne ST, Slifstein M, et al. (2005): Prediction of panic response to a respiratory stimulant by reduced orbitofrontal cerebral blood flow in panic disorder. Am J Psychiatry 162:1379-1381.

Kringelbach ML (2005): The human orbitofrontal cortex: Linking reward to hedonic experience. Nat Rev Neurosci 6:691-702.

Lammertsma AA, Hume SP (1996): Simplified reference tissue model for PET receptor studies. Neuroimage 4:153-158.

Liotti M, Mayberg HS, Brannan SK, McGinnis S, Jerabek P, Fox PT (2000): Differential limbic-cortical correlates of sadness and anxiety in healthy subjects: Implications for affective disorders. Biol Psychiatry 48:30-42.

Lorberbaum JP, Kose S, Johnson MR, Arana GW, Sullivan LK, Hamner MB, et al. (2004): Neural correlates of speech anticipatory anxiety in generalized social phobia. Neuroreport 15:2701-2705.

Martin-Ruiz R, Puig MV, Celada P, Shapiro DA, Roth BL, Mengod G, et al. (2001): Control of serotonergic function in medial prefrontal cortex by serotonin-2A receptors through a glutamate-dependent mechanism. J Neurosci 21:9856-9866.

Matarrese M, Sudati F, Soloviev D, Todde S, Turolla EA, Kienle MG, et al. (2002): Automation of [11C]acyl chloride syntheses using commercially available 11C-modules. Appl Radiat Isot 57:675-679.

McCarron JA, Turton DR, Pike VW, Poole KG (1996): Remotely-controlled production of the 5-HT1A receptor radioligand, [carbonyl-11C]-WAY100635, via 11Ccarboxylation of an immobilized Grignard reagent. J Labelled Comp Radiopharm 38:941-953.

Meijer OC, de Kloet ER (1998): Corticosterone and serotonergic neurotransmission in the hippocampus: Functional implications of central corticosteroid receptor diversity. Crit Rev Neurobiol 12:1-20.

Meijer OC, Williamson A, Dallman MF, Pearce D (2000): Transcriptional repression of the 5-HT1A receptor promoter by corticosterone via mineralocorticoid receptors depends on the cellular context. J Neuroendocrinol 12:245-254.

Meyer JH, Gunn RN, Myers R, Grasby PM, et al. (1999): Assessment of spatial normalization of PET ligand images using ligand-specific templates. Neuroimage 9:545-553.

Mikolajczyk K, Szabatin M, Rudnicki P, Grodzki M, Burger C (1998): A JAVA environment for medical image data analysis: initial application for brain PET quatitation. Med Inform (Lond) 23:207-214.

Milad MR, Quirk GJ (2002): Neurons in medial prefrontal cortex signal memory for fear extinction. Nature 420:70-74.

Milad MR, Vidal-Gonzalez I, Quirk GJ (2004): Electrical stimulation of medial prefrontal cortex reduces conditioned fear in a temporally specific manner. Behav Neurosci 118:389-394.

Morris JS, Büchel C, Dolan RJ (2001): Parallel neural responses in amygdala subregions and sensory cortex during implicit fear conditioning. Neuroimage 13:1044-1052. 
Neumeister A, Bain E, Nugent AC, Carson RE, Bonne O, Luckenbaugh DA, et al. (2004): Reduced serotonin type $1 \mathrm{~A}$ receptor binding in panic disorder. J Neurosci 24:589-591.

Parks CL, Robinson PS, Sibille E, Shenk T, Toth M (1998): Increased anxiety of mice lacking the serotonin1A receptor. Proc Natl Acad Sci U S A 95: 10734-10739.

Parsey RV, Oquendo MA, Ogden RT, Olvet DM, Simpson N, Huang YY, et al. (2006): Altered serotonin $1 \mathrm{~A}$ binding in major depression: A [carbonyl-C-11]WAY100635 positron emission tomography study. Biol Psychiatry 59(2):106-113.

Parsey RV, Oquendo MA, Simpson NR, Ogden RT, Van Heertum R, Arango V, et al. (2002): Effects of sex, age, and aggressive traits in man on brain serotonin 5-HT1A receptor binding potential measured by PET using [C-11]WAY-100635. Brain Res 954:173-182.

Parsey RV, Slifstein M, Hwang DR, Abi-Dargham A, Simpson N, Mawlawi O, et al. (2000): Validation and reproducibility of measurement of 5-HT1A receptor parameters with [carbonyl-11C]WAY-100635 in humans: Comparison of arterial and reference tissue input functions. J Cereb Blood Flow Metab 20:1111-1133.

Pine DS, Fyer A, Grun J, Phelps EA, Szeszko PR, Koda V, et al. (2001): Methods for developmental studies of fear conditioning circuitry. Biol Psychiatry 50:225-228.

Puig MV, Artigas F, Celada P (2005): Modulation of the activity of pyramidal neurons in rat prefrontal cortex by raphe stimulation in vivo: Involvement of serotonin and GABA. Cereb Cortex 15:1-14.

Rabiner EA, Bhagwagar Z, Gunn RN, Cowen PJ, Grasby PM (2004): Preferential 5-HT1A autoreceptor occupancy by pindolol is attenuated in depressed patients: Effect of treatment or an endophenotype of depression? Neuropsychopharmacology 29:1688-1698.

Rabiner EA, Gunn RN, Wilkins MR, Sargent PA, Mocaer E, Sedman E, et al. (2000): Drug action at the 5-HT(1A) receptor in vivo: Autoreceptor and postsynaptic receptor occupancy examined with PET and [carbonyl(11)C]WAY-100635. Nucl Med Biol 27:509-513.

Rabiner EA, Messa C, Sargent PA, Husted-Kjaer K, Montgomery A, Lawrence $A D$, et al. (2002): A database of [(11)C]WAY-100635 binding to 5-HT(1A) receptors in normal male volunteers: Normative data and relationship to methodological, demographic, physiological, and behavioral variables. Neuroimage 15:620-632.

Ramboz S, Oosting R, Amara DA, Kung HF, Blier P, Mendelsohn M, et al. (1998): Serotonin receptor $1 A$ knockout: An animal model of anxietyrelated disorder. Proc Natl Acad Sci U S A 95:14476-14481.

Riad M, Zimmer L, Rbah L, Watkins KC, Hamon M, Descarries L (2004): Acute treatment with the antidepressant fluoxetine internalizes 5-HT1 A autoreceptors and reduces the in vivo binding of the PET radioligand [18F]MPPF in the nucleus raphe dorsalis of rat. J Neurosci 24:5420-5426.

Robinson S, Hoheisel B, Windischberger C, Habel U, Lanzenberger R (2005): FMRI of the emotions: Towards an improved understanding of amygdala function. Current Medical Imaging Reviews 1:115-129.

Santana N, Bortolozzi A, Serrats J, Mengod G, Artigas F (2004): Expression of serotonin $1 \mathrm{~A}$ and serotonin2A receptors in pyramidal and GABAergic neurons of the rat prefrontal cortex. Cereb Cortex 14:1100-1109.

Sargent PA, Kjaer KH, Bench CJ, Rabiner EA, Messa C, Meyer J, et al. (2000): Brain serotonin $1 A$ receptor binding measured by positron emission tomog- raphy with [11C]WAY-100635: Effects of depression and antidepressant treatment. Arch Gen Psychiatry 57:174-180.

Schneider F, Weiss U, Kessler C, Muller-Gartner HW, Posse S, Salloum JB, et al. (1999): Subcortical correlates of differential classical conditioning of aversive emotional reactions in social phobia. Biol Psychiatry 45:863-871.

Sheehan DV, Lecrubier Y, Sheehan KH, Amorim P, Janavs J, Weiller E, et al. (1998): The Mini-International Neuropsychiatric Interview (M.I.N.I.): The development and validation of a structured diagnostic psychiatric interview for DSM-IV and ICD-10. J Clin Psychiatry 59 Suppl 20:22-33; quiz 34-57.

Shin LM, Wright Cl, Cannistraro PA, Wedig MM, McMullin K, Martis B, et al. (2005): A functional magnetic resonance imaging study of amygdala and medial prefrontal cortex responses to overtly presented fearful faces in posttraumatic stress disorder. Arch Gen Psychiatry 62:273-281.

Spielberger CD, Vagg PR (1984): Psychometric properties of the STAI: A reply to Ramanaiah, Franzen, and Schill. J Pers Assess 48:95-97.

Stein MB, Goldin PR, Sareen J, Zorrilla LT, Brown GG (2002): Increased amygdala activation to angry and contemptuous faces in generalized social phobia. Arch Gen Psychiatry 59:1027-1034.

Sullivan GM, Oquendo MA, Simpson N, Van Heertum RL, John Mann J, Parsey RV (2005): Brain serotonin(1A) receptor binding in major depression is related to psychic and somatic anxiety. Biol Psychiatry 58(12):947-954.

Talbot PS (2004): The molecular neuroimaging of anxiety disorders. Curr Psychiatry Rep 6:274-279.

Tauscher J, Bagby RM, Javanmard M, Christensen BK, Kasper S, Kapur S (2001a): Inverse relationship between serotonin 5-HT(1A) receptor binding and anxiety: A [(11)C]WAY-100635 PET investigation in healthy volunteers. Am J Psychiatry 158:1326-1328.

Tauscher J, Kapur S, Verhoeff NP, Hussey DF, Daskalakis ZJ, TauscherWisniewski S, et al. (2002): Brain serotonin 5-HT(1A) receptor binding in schizophrenia measured by positron emission tomography and [11C]WAY-100635. Arch Gen Psychiatry 59:514-520.

Tauscher J, Verhoeff NP, Christensen BK, Hussey D, Meyer JH, Kecojevic A, et al. (2001b): Serotonin 5-HT1A receptor binding potential declines with age as measured by [11C]WAY-100635 and PET. Neuropsychopharmacology 24:522-530.

Tillfors M, Furmark T, Marteinsdottir I, Fischer H, Pissiota A, Langstrom B, et al. (2001): Cerebral blood flow in subjects with social phobia during stressful speaking tasks: A PET study. Am J Psychiatry 158:1220-1226.

Tillfors M, Furmark T, Marteinsdottir I, Fredrikson M (2002): Cerebral blood flow during anticipation of public speaking in social phobia: A PET study. Biol Psychiatry 52:1113-1119.

Varnas K, Halldin C, Hall H (2004): Autoradiographic distribution of serotonin transporters and receptor subtypes in human brain. Hum Brain Mapp 22:246-260.

Veit R, Flor H, Erb M, Hermann C, Lotze M, Grodd W, et al. (2002): Brain circuits involved in emotional learning in antisocial behavior and social phobia in humans. Neurosci Lett 328:233-236.

Wright Cl, Martis B, McMullin K, Shin LM, Rauch SL (2003): Amygdala and insular responses to emotionally valenced human faces in small animal specific phobia. Biol Psychiatry 54:1067-1076. 